\title{
The Effect of Si-Doping on the Release of Antibiotic from Hydroxyapatite Coatings
}

\author{
Mirjam Lilja $^{1,2}$, Carl Lindahl ${ }^{3,4}$, Wei Xia ${ }^{3,4}$, Håkan Engqvist ${ }^{3}$, Maria Strømme ${ }^{{ }^{*}}$ \\ ${ }^{1}$ Division for Nanotechnology and Functional Materials, The Ångström Laboratory, Department of Engineering Sciences, Uppsala \\ University, Uppsala, Sweden; ${ }^{2}$ Sandvik Coromant AB, Stockholm, Sweden; ${ }^{3}$ Division for Applied Material Science, The Ångström \\ Laboratory, Department of Engineering Sciences, Uppsala University, Uppsala, Sweden; ${ }^{4}$ BIOMATCELL, VINN Excellence Center \\ of Biomaterials and Cell Therapy, Gothenburg, Sweden. \\ Email: *maria.stromme@angstrom.uu.se
}

Received April 23 ${ }^{\text {rd }}, 2013$; revised June $1^{\text {st }}, 2013$; accepted June $12^{\text {th }}, 2013$

Copyright (C 2013 Mirjam Lilja et al. This is an open access article distributed under the Creative Commons Attribution License, which permits unrestricted use, distribution, and reproduction in any medium, provided the original work is properly cited.

\begin{abstract}
Herein, we show that incorporation of ions during biomimetic coating deposition may be utilized to tailor the drug loading capacity of hydroxyapatite (HA) coatings. Pure biomimetic HA (HA-B) and Si-doped equivalents (SiHA-B) where deposited by a biomimetic process onto titanium dioxide covered titanium substrates. The antibiotic Cephalothin was incorporated into the coatings by adsorptive loading and the release was studied in-vitro. SiHA-B coatings exhibited superior drug incorporation capacity compared to pure HA-B coatings, resulting in a drug release profile dominated by an initial 10 min burst effect while a more prolonged 10 hour release was observed from HA-B coatings. The results emphasize the possibility to impact the drug release kinetics from implant coatings by selective doping elements and the use of thin, biomimetic HA-coatings as drug delivery vehicles. Functionalizing metal implants with SiHA-B coatings presents an interesting strategy towards creating synergetic effects through ion- and antibiotic release and, hence, contributing both towards preventing post-surgical infections and at the same time enhancing the bone-bonding ability.
\end{abstract}

Keywords: Titanium Dioxide; Hydroxyapatite; Cephalothin; Drug Release; Si-Doping

\section{Introduction}

The use of bioactive hydroxyapatite (HA) coatings on metal implant surfaces have been reported to improve fixation in orthopaedic implants, especially during the early stage of healing $[1,2]$. To further enhance the bonebonding ability at the bone/implant interface, anionic and cationic substitutions have been investigated to mirror the mineral component of the bone more accurately [3]. Studies have shown that HA coatings containing foreign ions can improve the cell proliferation and in-vivo bone tissue response [4-6]. Strontium $(\mathrm{Sr})$ has been proven to increase bone strength and reduce bone resorption $[7,8]$, whereas silicon ( $\mathrm{Si}$ ) has the ability to increase the bone mineralization rate and enhance the osteoblast proliferation [9], differentiation and collagen production [10,11]. Despite the promising properties of HA coatings in terms of early bone appositions and long-term fixation, the osseointegration process can be hampered by the presence of bacteria in the peri-implant bone healing area [12].

${ }^{*}$ Corresponding author.
HA coatings deposited by biomimetic methods (HA-B) have been tested successfully as drug delivery vehicle for, e.g., bisphosphonates and antibiotics in order to promote bone formation around the implant site or reduce the risk of infections [12-19]. Biomimetic deposition is a coating method carried out at ambient temperature [20] and it allows for production of nanoporous, calcium-deficient HA-B coatings on titanium implants surfaces [21,22]. Crystalline anatase and rutile phases of $\mathrm{TiO}_{2}$ have shown superior bioactivity compared to native titanium oxide surfaces [23-26] and are, thus, suitable materials for implant surfaces.

Parameters, such as solubility, binding capacity and net charge of the drug have been shown to play an important role for the drug release from implant surfaces [27, 28]. Based on the promising in-vivo results of ion-doped HA-B coatings, the combined use of biologically active ions and antibiotics incorporated into HA-B presents an interesting path to follow. A dual release strategy is expected to stimulate and improve cell proliferation while at the same time delivering pharmaceutical agents to 
combat and prevent implant related infections. Compared to pure HA, ion-doped HA has a different solubility, crystallinity and topography, which are expected to influence the bone response around the implant [29] as well as the drug release.

The aim of this study was to investigate the impact of Si-doping on the microstructure of biomimetically deposited HA coatings and to evaluate the effect on the drug loading and release properties of these in order to promote a beneficial, dual effect as described above.

\section{Materials and Methods}

\subsection{Coating Deposition}

Square substrates $(20 \times 20 \mathrm{~mm})$ of commercially available titanium grade 4 were coated with an anatase phase dominated crystalline $\mathrm{TiO}_{2}$ by cathodic arc evaporation during a deposition time of $20 \mathrm{~min}$, as described elsewhere [30]. The $\mathrm{TiO}_{2}$ coated substrates were placed, either perpendicular standing or horizontally laying (denoted as (p) or (h), respectively), into plastic tubes filled with $40 \mathrm{ml}$ Dulbecco's phosphate buffered saline (PBS) (Sigma) for 7 days at $60^{\circ} \mathrm{C}$ for deposition of a HA-B layer on the surfaces. SiHA-B coatings were obtained by immersing the $\mathrm{TiO}_{2}$ coated samples into modified PBS (Si-PBS) with a silicate ion concentration of $2 \mathrm{mM}$, as described earlier [31].

The coated samples were subjected to a drug loading procedure following the HA-B and SiHA-B coating deposition where they were placed for 1 hour in $40 \mathrm{ml}$ PBS containing $1 \mathrm{mg}$ Cephalothin (Sigma) at $37^{\circ} \mathrm{C}$.

\subsection{Characterization}

X-ray diffraction (XRD) measurements of the deposited SiHA-B and HA-B coatings were performed using a Siemens D5000 diffractometer operating with $1^{\circ}$ grazing incidence angle in parallel beam geometry using $\mathrm{CuK} \alpha$ radiation (wavelength $\lambda$ of $1.540598 \AA$ ). A step size of $0.1^{\circ}$ and a scan step time of $4 \mathrm{~s}$ were used for the scans recorded between $20^{\circ}$ and $34^{\circ} 2 \theta$. The morphology of the coatings was examined by a Zeiss 40 Scanning electron microscope (SEM). SEM images of SiHA-B and HA-B cross sections obtained by ion milling (E-3500, Hitachi) were recorded to evaluate the thicknesses and structures of the deposited coatings.

\subsection{Antibiotic Release}

The release of Cephalothin was analyzed with UV-vis absorption spectroscopy (UV-1650PC, Shimadzu) at a wavelength of $238 \mathrm{~nm}$. During the release experiments 2 plates were placed in $10 \mathrm{ml}$ deionized water that was circulated through the measuring cell using a peristaltic pump. The adsorption was automatically measured at time intervals of 5 min under the total measurement time of $16 \mathrm{~h}$. The measurements were carried out in triplicates to confirm the reproducibility of the release kinetics. After the release measurements the coatings were dissolved in hydrochloric acid to confirm the absence of drugs remaining in the coatings.

\section{Results and Discussion}

The XRD patterns of $\mathrm{TiO}_{2}$ coated substrates after being immersed for 7 days in PBS or Si-PBS are presented in Figure 1 and confirm the presence HA in both coating types. SEM images recorded on cross sections of the biomimetically deposited coatings show rather thin HA-B and SiHA-B coatings with an average thickness of only 200 - 250 nm, Figures 2(a) and (c). In agreement with literature data [31] both coatings display a flake-like morphology, Figures 2(b) and (d). The images reveal a porous network of small crystals for both coating types. The pure HA-B coatings appear to have a slightly denser topography (Figure 2(c)) compared to SiHA-B coatings (Figure 2(d)), and the cross section images support this by displaying a denser network of crystals at the interface towards the underlying $\mathrm{TiO}_{2}$ surface for HA-B coatings, Figure 2(a).

Figure 3 shows typical release curves in water from HA-B and SiHA-B coatings loaded with Cephalothin. The displayed curves represent the release of all drugs that were incorporated during the drug loading experiment; no residual drug could be detected in any of the coatings after $16 \mathrm{~h}$ of release.

A rapid release of the drug is observed within the first $10 \mathrm{~min}$ for all sample types, followed by a slower, prolonged release period continuing for about 10 hours. The total amount released from the SiHA-B coatings is larger than from the HA-B coatings deposited under compara-

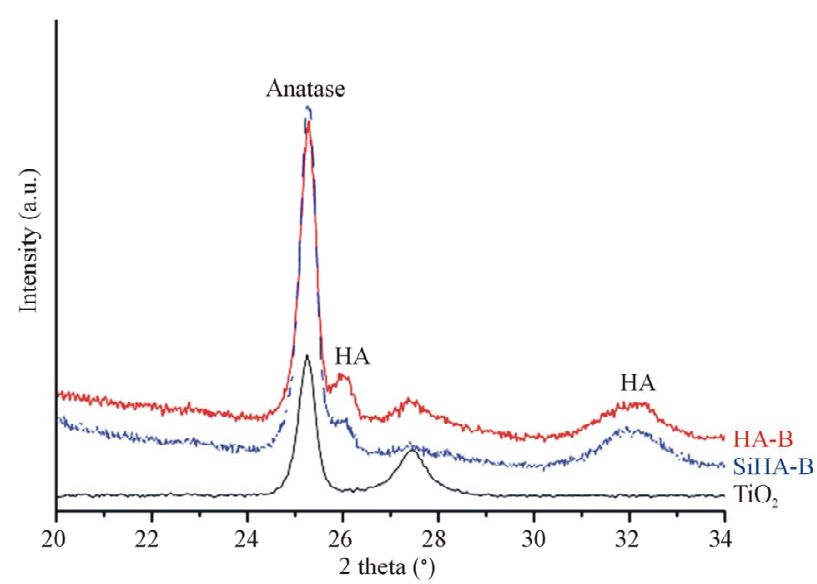

Figure 1. XRD patterns of $\mathrm{TiO}_{2}$ covered titanium grade 4 substrates after immersion for 7 days in $60^{\circ} \mathrm{C}$ heated PBS (HA-B) and Si-enriched PBS (SiHA-B). A $\mathrm{TiO}_{2}$ surface is displayed as reference. 


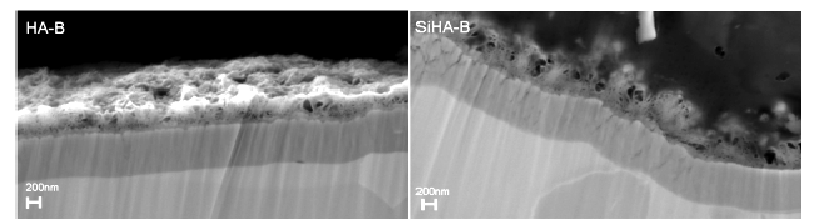

(a)

(c)

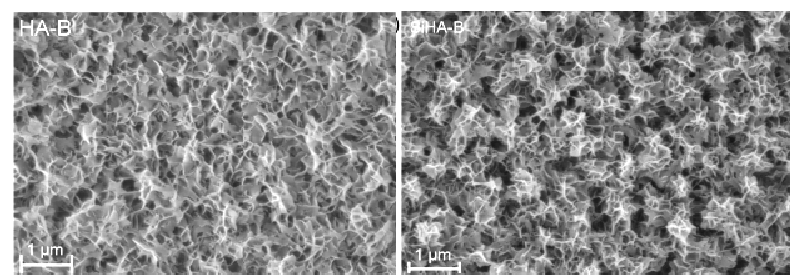

(b)

(d)

Figure 2. SEM images of cross-sections ((a) and (c)) and topography ((b) and (d)) of HA-B (left column) and SiHA-B coated $\mathrm{TiO}_{2}$ surfaces (right column) after an immersion time of 7 days in perpendicular position (p) in PBS and Si-enriched PBS, respectively.

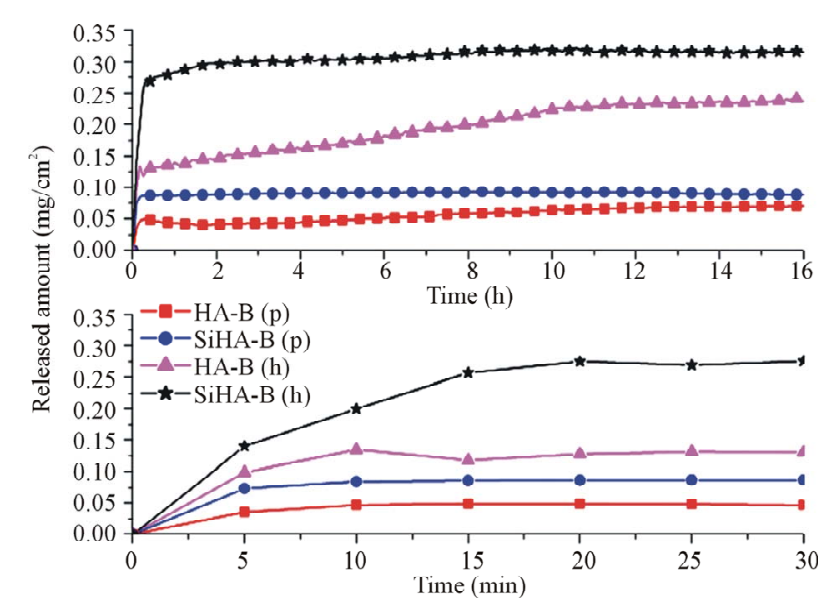

Figure 3. Initial release curves (lower panel) and release during the entire time period under study (upper panel) presenting the amount of Cephalothin released in roomtempered deionized water per surface area for SiHA-B and HA-B samples coated in the displayed positions ( $p$ or $h$ ). All samples were adsorptively loaded with Cephalothin for $1 \mathrm{~h}$ at $37^{\circ} \mathrm{C}$.

ble conditions. The major part of the drug content of the former is, however, released during the initial $10 \mathrm{~min}$ whereas the latter coatings release more during the 10 min - 10 h time period. Furthermore, samples placed horizontally (h) in PBS during the coating deposition process have a significantly higher drug incorporation capacity than perpendicularly (p) placed samples. This is most likely explained by a higher HA growth rate for (h)-samples due to gravity; a larger amount of sedimenting crystals precipitated in the solutions will meet a horizontally placed sample as compared to the amount encountering a perpendicularly placed one and, thus, form a thicker coating with larger incorporation capacity. SEM analysis (not shown) indeed confirms the fact that the (h)-samples are somewhat thicker than the (p)-samples. Furthermore, the sample surfaces of the latter ones showed a rougher topography originating from clearly distinguishable HA precipitates on top of a more uniform HA coating.

The results highlight the possibility to impact the drug loading capacity and the release profile of biomimetically deposited HA coatings by incorporating biologically active ions during biomimetic deposition. Si incorporation clearly contributes towards forming a coating structure with an increased drug incorporation capacity and also a faster release process. The specific surface area of biomimetically deposited HA coatings has been shown to increase linearly with the deposition time [20], whereas HA crystal size decreases significantly when HA is substituted with Sr, F and Si ions [31,32]. As well, silicate groups produce an increase in negative surface charge [33]. The average crystal size of Si substituted HA was measured to decrease by about $28 \%$ [31] which may hence, offer a larger surface area for the incorporation of Cephalothin. The surface topographies observed in the SEM images (Figures 2(b) and (d)), displaying a more dense structure for the HA-B coatings as compared to the SiHA$B$ coatings supports this. In addition to an increased surface area, substituting HA with Si ions may provide a surface chemistry that affects the interaction and binding between antibiotics and SiHA-B coating and, hence, the drug release kinetics. Cephalothin has one carboxylic acid group that can interact with calcium present in HA [34]. The HA surface area and surface charge as well as the charge of the adsorbed molecules and their mode of interaction with the HA surface, have been shown to influence the drug adsorption and release kinetics [35]. In SiHA-B coatings, $\mathrm{Si}$ ions replace $\mathrm{PO}_{4}^{3-}$ groups [36], resulting in an increased negative surface charge [33] and an insignificant change in the $\mathrm{Ca} / \mathrm{P}$ ratio [37]. With similar amounts of $\mathrm{Ca}$ present in the coating structure for both coating types, it may be expected that the surface chemistry of the SiHA-B samples restricts the interaction with and binding of drug molecules to calcium ions in the coating. As a result, Cephalothin is repelled and released quickly by the negatively charged SiHA-B coatings, as evidenced by the burst release during the first 10 min, Figure 3, while the binding of the drug to pure HA$\mathrm{B}$ coatings allows for a prolonged release. These observations are in agreement with release profiles obtained of Zn-doped HA, where such doping resulted in higher incorporation and faster release of ciprofloxacin [38].

The use of antibiotics with positive charge at neutral $\mathrm{pH}$, such as Tobramycin [39], could present one way to impact the affinity towards the negatively charged SiHA$\mathrm{B}$ surface and hence a possibility to obtain drug release profiles offering both initial burst and sustained release. The total amounts of Cephalothin released from both 
HA-B and SiHA-B are similar to amounts previously proven to be sufficient for inhibition of $S$. aureus and $S$. epidermidis [17] which are common causes of implant related infections.

\section{Conclusion}

We show that incorporation of ions during biomimetic coating deposition may be utilized to tailor the surface area and, thus, the drug loading capacity, of HA coatings. Incorporation of Si ions in HA resulted in a higher uptake and a faster release of Cephalothin as compared to pure HA. In agreement with earlier studies the measured amounts of Cephalothin released are sufficient to inhibit the growth of $S$. aureus and $S$. epidermidis. Functionalizing implant surfaces with biomimetically deposited HA coatings, which combine the release of both bioactive ions and antibiotics, present an interesting path to follow in the development of dual-activity implants contributing towards both bone tissue regeneration and minimizing implant related infections.

\section{Acknowledgements}

The Swedish Research Council, the Carl Trygger Foundation, the Göran Gustafsson Foundation, the Swedish Foundation for Strategic Research and Vinnova are acknowledged for financially supporting our research.

\section{REFERENCES}

[1] K. Degroot, R. Geesink, C. Klein and P. Serekain, "Plasma Sprayed Coatings of Hydroxyapatite," Journal of Biomedical Materials Research, Vol. 21, No. 12, 1992, pp. 1375-1381.

[2] W. Jaffe and D. Scott, "Total Hip Arthroplasty with Hydroxyapatite-Coated Prosthesis," Journal of Bone and Joint Surgery, Vol. 78, No. 12, 1996, pp. 1918-1934.

[3] J. H. Shepherd, D. V. Shepherd and S. M. Best, "Substituted Hydroxyapatites for Bone Repair," Journal of Materials Science-Materials in Medicine, Vol. 23, No. 10, 2012, pp. 2335-2347.

[4] M. Vallet-Regi and D. Arcos, "Silicon Substituted Hydroxyapatites. A Method to Upgrade Calcium Phosphate Based Implants," Materials Chemistry, Vol. 15, 2005, pp. 1509-1516.

[5] A. Oliveira, R. Reis and P. Li, "Strontium-Substituted Apatite Coating Grown on Ti6Al4V Substrate through Biomimetic Synthesis," Journal of Biomedical Materials Research B, Vol. 83, No. 1, 2007, pp. 258-265.

[6] S. Cazalbou, C. Combes and C. Rey, "Biomimetic Approach for Strontium Containing Ca-P Bioceramics with Enhanced Biological Activity,” Key Engineering Materials, Vol. 92, No. 13, 2001, pp. 192-195.

[7] P. Ritger and N. Peppas, “A Simple Equation for Description of Solute Release I. Fickian and Non-Fickian Release from Non-Swellable Devices in the Form of Slabs, Spheres,
Cylinders or Discs,” Journal of Control Release, Vol. 5 , No. 1, 1987, pp. 23-36.

[8] N. Peppas, "Analysis of Fickian and Non-Fickian Drug Release from Polymers, "Pharmaceutica Acta Helvetiae, Vol. 60, No. 4, 1985, pp. 110-111.

[9] E. Zhang and C. Zou, "Porous Titanium and Silicon-Substituted Hydroxyapatite Biomodification Prepared by a Biomimetic Process: Characterization and in Vivo Evaluation," Acta Biomaterialia, Vol. 5, No. 5, 2009, pp. 1732-1741.

[10] K. Schantz and D. B. Milne, "Growth-Promoting Effects of Silicon in Rats,” Nature, Vol. 239, No. 5371, 1972, pp. 333-334.

[11] K. A. Hing, P. A. Revell, N. Smith and T. Buckland, "Effect of Silicon Level on Rate, Quality and Progression of Bone Healing within Silicate-Substituted Porous Hydroxyapatite Scaffolds,” Biomaterials, Vol. 27, No. 29, 2006; pp. 5014-5026.

[12] M. Stigter, J. Bezemer, K. de Groot and P. Layrolle, "Incorporation of Different Antibiotics into Carbonated Hydroxyapatite Coatings on Titanium Implants, Release and Antibiotic Efficacy,” Journal of Control Release, Vol. 99, No. 1, 2004, pp. 127-137.

[13] S. Piskounova, J. Forsgren, U. Brohede, H. Engqvist and M. Strømme, "In Vitro Characterization of Bioactive Titanium Dioxide/Hydroxyapatite Surfaces Functionalized with BMP-2," Journal of Biomedical Materials Research $B$, Vol. 91B, No. 2, 2009, pp. 780-787.

[14] J. Forsgren, U. Brohede, H. Engqvist and M. Strømme, "Co-Loading of Bisphosphonates and Antibiotics to a Biomimetic Hydroxyapatite Coating,” Biotechnological Letters, Vol. 33, No. 6, 2011, pp. 1265-1268.

[15] M. Lilja, J. Sörensen, U. Brohede, M. Åstrand, J. Arnoldi, P. Procter, H. Steckel and M. Strømme, "Drug Loading and Release of Tobramycin from Hydroxyapatite Coated Fixation Pins," Journal of Materials Science-Materials in Medicine, 2013, in press. doi:10.1007/s10856-013-4979-1

[16] M. Stigter, K. de Groot and P. Layrolle, “Incorporation of Tobramycin into Biomimetic Hydroxyapatite Coating on Titanium," Biomaterials, Vol. 23, No. 20, 2002, pp. 4143-4153.

[17] U. Brohede, J. Forsgren, S. Roos, A. Mihranyan, H. Engqvist and M. Strømme, "Multifunctional Implant Coatings Providing Possibilities for Fast Antibiotics Loading with Subsequent Slow Release,” Journal of Materials Science -Materials in Medicine, Vol. 20, No. 9, 2009, pp. 18591867.

[18] J. Åberg, U. Brohede, A. Mihranyan, M. Strømme and H. Engqvist, "Bisphosphonate Incorporation in Surgical Implant Coatings by Fast Loading and Co-Precipitation at Low Drug Concentrations," Journal of Materials Science -Materials in Medicine, Vol. 20, No. 10, 2009, pp. 2053-2061.

[19] J. Forsgren, U. Brohede, S. Piskounova, A. Mihranyan, S. Larsson, M. Strømme and H. Engqvist, "In Vivo Evaluation of Functionalized Biomimetic Hydroxyapatite for Local Delivery of Active Agents,” Biomater Nanobiotech, Vol. 2, No. 2, 2011, pp. 149-154.

[20] A. Mihranyan, J. Forsgren, M. Strømme and H. Engqvist, 
“Assessing Surface Area Evolution during Biomimetic Growth of Hydroxyapatite Coatings,” Langmuir, Vol. 25, No. 3, 2009, pp. 1292-1295.

[21] T. Kokubo, H. Kushitani, S. Sakka, T. Kitsugi and T. Yamamuro, "Solutions Able to Reproduce in Vivo SurfaceStructure Changes in Bioactive Glass-Ceramic A-W," Journal of Biomedical Materials Research, Vol. 4, No. 6, 1990, pp. 721-734.

[22] S. Kuroda, A. S. Virdi, P. Li, K. E. Healy and D. R. Sumner, "A Low Temperature Biomimetic Calcium Phosphate Surface Enhances Early Implant Fixation in a Rat Model," Journal of Biomedical Materials Research, Vol. 70A, No. 1, 2004, pp. 66-73.

[23] B. C. Yang, M. Uchidab, H. M. Kimc, X. Zhanga and T. Kokubo, "Preparation of Bioactive Titanium Metal via Anodic Oxidation Treatment," Biomaterials, Vol. 25, No. 6, 2004, pp. 1003-1010.

[24] W. Zhou, X. Zhong, X. Wu, L. Yaun, Q. Shu, Y. Xia and K. Ostrikov, "Plasma-Controlled Nanocrystallinity and Phase Composition of $\mathrm{TiO}_{2}$ : A Smart Way to Enhance Biomimetic Response," Journal of Biomedical Materials Research, Vol. 81A, No. 2, 2007, pp. 453-464.

[25] U. Brohede, S. Zhao, F. Lindberg A. Mihranyan, J. Forsgren, M. Strømme and H. Engqvist, "A Novel Graded Bioactive High Adhesion Implant Coating,” Applied Surface Science, Vol. 225, No. 17, 2009, pp. 7723-7728.

[26] M. Lilja, A. Genvad, M. Åstrand, M. Strømme and H. Engqvist, "Influence of Microstructure and Chemical Composition of Sputter Deposited $\mathrm{TiO}_{2}$ Thin Films on in Vitro Bioactivity," Journal of Materials Science-Materials in Medicine, Vol. 22, No. 12, 2011, pp. 2727-2734.

[27] A. Lebugle, A. Rodrigues, P. Bonnevialle, J. J. Voigt, P. Canal and F. Rodriguez, "Study of Implantable Calcium Phosphate Systems for the Slow Release of Metho-Trexate," Biomaterials, Vol. 23, No. 16, 2002, pp. 3517-3522.

[28] A. E. Burgos, J. C. Belchior and R. D. Sinisterra, "Controlled Release of Rhodium (II) Carboxylates and Their Association Complexes with Cyclodextrins from HydroxyApatite Matrix,” Biomaterials, Vol. 23, No. 12, 2002, pp. 2519-2526.

[29] I. Gibson, S. Best and W. Bonfield, "Chemical Characterization of Silicon-Substituted Hydroxyapatite," Journal of Biomedical Materials Research, Vol. 44, No. 4, 1996, pp. 422-428.

[30] M. Lilja, K. Welch, M. Åstrand, H. Engqvist and M. Strømme, "Effect of Deposition Parameters on the Photocatalytic Activity and Bioactivity of $\mathrm{TiO}_{2}$ Thin Films Deposited by Vacuum Arc on Ti-6Al-4V Substrates,” Journal of Biomedical Materials Research B, Vol. 100, No. 4, 2012, pp. 1078-1085.

[31] W. Xia, C. Lindahl, C. Persson, P. Thomsen, J. Lausmaa and H. Engqvist, "Changes of Surface Composition and Morphology after Incorporation of Ions into Biomimetic Apatite Coatings," Journal of Biomaterials and Nanobiotechnology, Vol. 1, No. 1, 2010, pp. 7-16.

[32] C. Lindahl, W. Xia, J. Lausmaa, P. Borchardt and H. Engqvist, "Strontium and Silicon Co-Doped Apatite Coating: Preparation and Function as Vehicles for Ion Delivery," Journal of Biomaterials and Nanobiotechnology, Vol. 3, No. 3, 2012, pp. 335-341.

[33] C. M. Botelho, M. A. Lopes, I. R. Gibson, S. M. Best and J. D. Santos, "Structural Analysis of Si-Substituted Hydroxyapatite: Zeta Potential and X-Ray Photoelectron Spectroscopy," Journal of Materials Science-Materials in Medicine, Vol. 13, No. 12, 2002, pp. 1123-1127.

[34] W. H. Streng, "Microionization Constants of Commercial Cephalosporins," Journal of Pharmaceutical Sciences, Vol. 67, No. 5, 1978, pp. 666-669.

[35] B. Palazzo, M. Iafisco, M. Laforgia, N. Margiotta, G. Natile, C. L. Bianchi, D. Walsh, S. Mann and N. Roveri, "Biomimetic Hydroxyapatite-Drug Nanocrystals as Potential Bone Substitutes with Antitumor Drug Delivery Properties," Advanced Functional Materials, Vol. 17, No. 13, 2007, pp. 2180-2188.

[36] T. Leventouri, C. E. Bunaciu and V. Perdikatsis, "Neutron Powder Diffraction Studies of Silicon-Substituted Hydroxyapatite," Biomaterials, Vol. 24, No. 23, 2003, pp. 4205-4211.

[37] C. Lindahl, W. Xia, J. Lausmaa and H. Engqvist, "Incorporation of Active Ions into Calcium Phosphate Coatings, Their Release Behavior and Mechanism,” Biomedical Materials, Vol. 7, No. 4, 2012, Article ID: 045018.

[38] G. D. Venkatasubbu, S. Ramasamy, V. Ramakrishnan and J. Kumar, "Nanocrystallinehydroxyapatite and Zinc-Doped Hydroxyapatite as Carrier Material for Controlled Delivery of Ciprofloxacin,” Biotech, Vol. 1, No. 3, 2011, pp. 173-186.

[39] Y. Liu, P. Layrolle, J. de Bruijn, C. van Blitterswijk and K. de Groot, "Biomimetic Coprecipitation of Calcium Phosphate and Bovine Serum Albumin on Titanium Alloy," Journal of Biomedical Materials Research, Vol. 57, No. 3, 2001, pp. 327-335. 